\title{
LAPAROCOPIC URETERAL REIMPLANTATION IN URETERAL STENOSIS AFTER GYNECOLOGIC LAPAROSCOPIC SURGERY
}

\author{
ANIBAL W. BRANCO, ALCIDES J. BRANCO FILHO, WILLIAM KONDO \\ Department of Urology and General Surgery, Vita Hospital and Cruz Vermelha Hospital, Curitiba, \\ Paraná, Brazil
}

\begin{abstract}
Pelvic surgery is the most common cause of iatrogenic ureteral injury, and traditionally repair of such injuries requires laparotomy. We report the case of a 48-year-old woman with an iatrogenic ureteral injury after laparoscopic ophorectomy which was laparoscopically reimplanted using the Lich-Gregoire technique. Total operating time was 150 minutes and estimated blood loss was 100 $\mathrm{mL}$. Two months after surgery she is asymptomatic with normal renal function.
\end{abstract}

Key words: ureter; iatrogenic disease; reconstructive surgical procedures; laparoscopy Int Braz J Urol. 2005; 31: 51-53

\section{INTRODUCTION}

The incidence of laparoscopic ureteral injuries in pelvic surgery range from less than $1 \%$ to $2 \%$ and laparoscopically assisted vaginal hysterectomy is the leading procedure in which injury occurs (1). Intraoperative injury to the ureter may result from ligation, angulation, transection, laceration, crush, ischemia, and resection. Most cases are only identified postoperatively and traditionally surgical repair is performed by laparotomy. We present a case of an iatrogenic ureteral injury managed laparoscopically by ureteral reimplantation.

\section{CASE REPORT}

A 48-year-old white woman underwent a laparoscopic oophorectomy for an ovarian cyst and 4 months after the surgical procedure she came to our service complaining about pain in her right flank, chills and fever.

Microscopic urinalysis revealed bacteriuria and pyuria, and urine culture showed a growth of E. coli. Ultrasonography showed a right pelviocaliceal dilatation and excretory urography demonstrated a functional exclusion of the right kidney. Magnetic resonance imaging urography identified right ureteral stenosis just after crossing the iliac vessels. Technetium-99m dimercaptosuccinic acid (Tc-99m DMSA) scintigraphy showed relative renal function of $20 \%$ in the right kidney (Figure-1).

The patient underwent laparoscopic ureteral reimplatation according to Lich-Gregoir technique. The patient was placed in a 45-degrees lateral decubitus position and a $10 \mathrm{~mm}$ trocar was placed in the periumbilical area for the 30-degree laparoscope. Another $10 \mathrm{~mm}$ trocar was placed in the anterior axillary line $4 \mathrm{~cm}$ below the umbilical level and a $5 \mathrm{~mm}$ trocar was placed in the midline, approximately halfway between the umbilicus and the pubis. The abdominal cavity was inspected and intraperitoneal adhesions in the pelvis were identified. The right colon was reflected and the dilated ureter was isolated. The ureteral dissection in the inferior direction showed a fibrous area at the level of the iliac vessels. The ureter was sectioned proximally to the obstruction site and ureteral reimplatation was performed with the Lich-Gregoire technique. The total operat- 


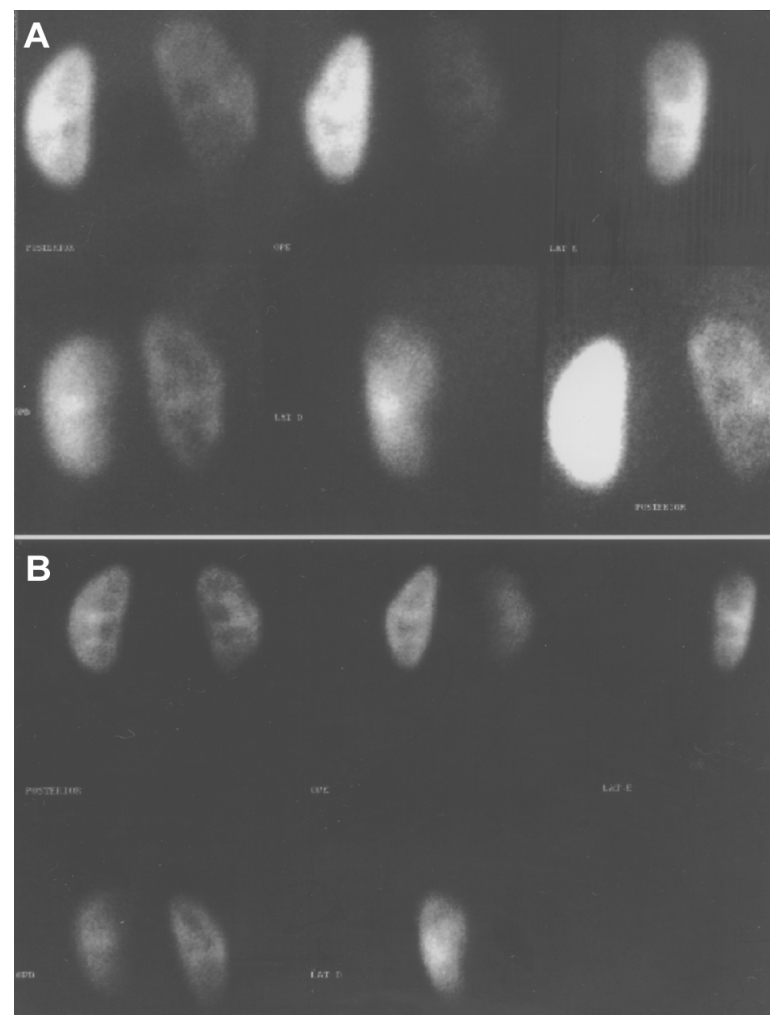

Figure 1 - A) Preoperative Tc-99m DMSA scintigraphy detected right renal parenchymal scars and a normal left kidney. The quantification of relative renal function based on DMSA uptake showed to be $20 \%$ on the right kidney and $80 \%$ on the left. B) Postoperative DMSA scintigraphy demonstrated an improvement in relative renal function, with relative function of the right kidney of $45.5 \%$.

ing time was 150 minutes and the estimated blood loss was $100 \mathrm{~mL}$. There were no intraoperative or postoperative complications and the patient was discharged 36 hours after the surgical procedure with the indwelling catheter being removed on day 5 .

One month after surgery, the patient had negative urine cultures and an unremarkable intravenous urogram, except for a minimal delay in filling of the collecting system with contrast material and residual ureteral dilatation (Figure-2).

In the second postoperative month the patient was asymptomatic and was submitted to another DMSA scintigraphy which showed a right relative function of $45.5 \%$ (Figure-1).

\section{COMMENTS}

The concepts and techniques of the ureteroneocystostomy, most commonly performed for the correction of vesicoureteral reflux in children, are also applicable to ureteral reimplantation for the repair of ureteral injuries, including stricture and intraoperative injury (2). A variety of techniques have been described and we reported a case successfully managed using a laparoscopic Lich-Gregoire procedure.

Most of the experimental studies report a reduction of adhesion formation after laparoscopic surgery compared to open surgery, and we did not find any difficulty in performing the laparoscopic repair after the gynecologic laparoscopic surgery.

Although abdominal open surgeries cause adhesions that may render subsequent laparoscopic access and dissection problematic, we support the opinion that laparoscopy can be done even after open surgeries. Parsons et al. (3) analyzed the effect of a previous abdominal surgery on urological laparoscopy and they concluded that it does not ap- 


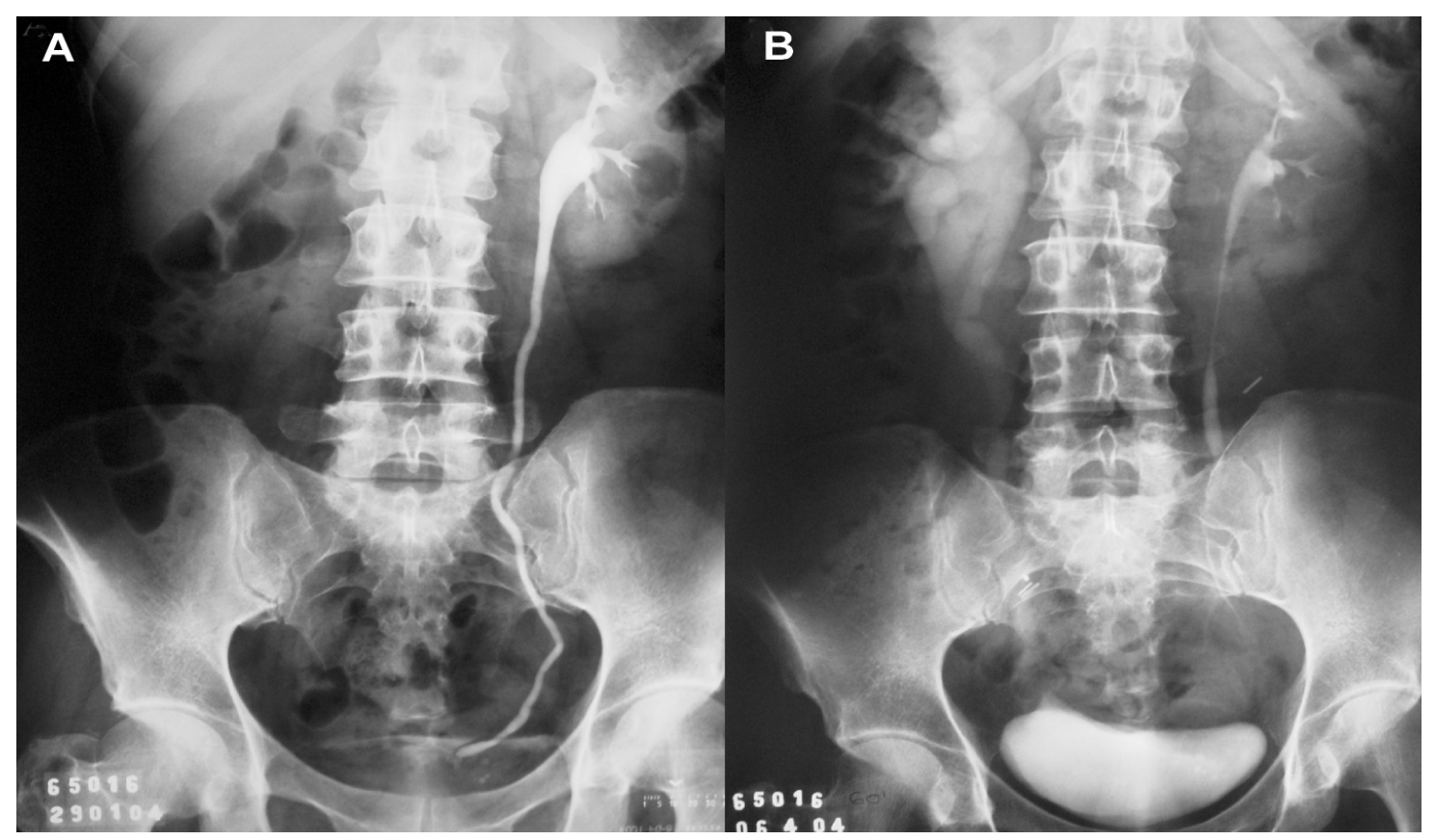

Figure 2 - A) Preoperative intravenous pyelogram showed asymmetric renal enhancement. The right kidney was poorly enhanced 9 hours after iodine-based contrast material injection, and the right pelviocaliceal system and ureter were not enhanced on this exam. B) Postoperative intravenous pyelogram 30 days after surgery demonstrated mild right renal enlargement associated with delayed excretion and dilatation of the right collecting system and upper third of the ureter, compatible with post-surgical status.

pear to adversely affect the performance of a subsequent urological laparoscopy. So, laparoscopic ureteral repair can be done after open and laparoscopic ureteral injuries.

In our literature review, it seems that this is the first case of ureteral reimplantation by laparoscopic approach after iatrogenic ureteral injury. Despite the limited experience, laparoscopic repair of ureteral injuries seems to be feasible and safe.

\section{REFERENCES}

1. Ostrzenski A, Radolinski B, Ostrzenska KM: A review of laparoscopic ureteral injury in pelvic surgery. Obstet Gynecol Surv. 2003; 58: 794-9.

2. Koo HP, Bloom DA: Lower ureteral reconstruction. Urol Clin North Am. 1999; 26: 167-73.

3. Parsons JK, Jarrett TJ, Chow GK, Kavoussi LR: The effect of previous abdominal surgery on urological laparoscopy. J Urol. 2002; 168: 2387-90.

Received: June 11, 2004 Accepted after revision: September 8, 2004

\section{$\overline{\text { Correspondence address: }}$}

Dr. Anibal Wood Branco

Rua das Palmeiras, 170 / 201

Curitiba, PR, 80620-210, Brazil

E-mail: anibal@awbranco.com.br 